\title{
Estudio filosófico sobre el sacrificio ${ }^{1}$
}

\author{
Maximiliano E. Korstanje²
}

\begin{abstract}
Resumen
La pérdida de cualquier familiar cercano implica un fuerte trauma para la persona. Pero de los estados que una sociedad confiere a quienes han perdido a un ser querido, no existe ninguno que pueda darse a quienes experimentan la muerte de un hijo. Esta realidad, innombrable desde el lenguaje, se remite a un miedo primigenio que aterroriza a todas las sociedades industriales. Si bien existen diversas explicaciones psicologistas sobre el tema, no menos cierto es que existieron en otro tiempo sociedades que gustosas sacrificaban a sus propios hijos. Esta dicotomía, planteada en términos antropológicos y sociales, permite comprender por qué sentimos pánico cuando nuestros hijos están en peligro. La tesis que este trabajo defiende es que existió un quiebre epistemológico durante el crecimiento de la sociedad industrial cuyo fin fue disciplinar y adoctrinar tanto a niños como a mujeres. La figura del buen hombre que trabaja por su familia no solo posibilitó el crecimiento capitalista sino que consolidó la lógica de dominación de lo masculino sobre otras formas de identidad.
\end{abstract}

Palabras Clave: sacrificio de niños, miedo a la muerte, industrialismo, relaciones laborales.

\begin{abstract}
The loss of any close relative means a trauma for any person, but there is no social status whatsoever to designate the loss of a child. The fact this is an unmentionable issue comes from a primitive fear scaring industrial societies. There are currently different psychological explanations for this phenomenon and there were in the past societies which happily would sacrifice their own children. Anthropological and social explanations allow us to understand why we panic when one of our children are in danger. This article suggests there was an epistemological break during the development of industrial societies which objective was to discipline and indoctrinate children and women. The image of the good man who works to support his family not only favoured the development of capitalism but also consolidated the supremacy of the masculine over other forms of identity.
\end{abstract}

Key words: children's sacrifice; fear of death; industrialism; workplace relations 


\begin{abstract}
Resumem
A perda de qualquer familiar próximo implica um forte trauma para a pessoa. Mais, dos estados que uma sociedade confere a quem tem perdido um ser querido, não existe nenhum que possa se dar a quem experimenta a morte de um filho. Esta realidade, innombrable desde o linguajar, se remite a um medo primigenio que aterroriza a todas as sociedades industriais. Si bem existem diversas explicações psicologistas sobe o tema, não menos certo é que existiram em outro tempo sociedades que gostosas sacrificavam seus próprios filhos. Esta dicotomia, proposta em termos antropológicos e sociais, permite compreender por que sentimos pânico quando nossos filhos estão em perigo. A tese que este trabalho defende é que existiu um quebre epistemológico durante o crescimento da sociedade industrial onde a finalidade foi disciplinar e doutrinar tanto a crianças como mulheres. A figura do bom homem que trabalha pela sua família não só possibilitou o crescimento capitalista sino que consolidou a lógica de dominação do masculino sobre outras formas de identidade.
\end{abstract}

Palavras Chave: sacrifício de crianças, medo a morte, industrialismo, relações laborais.

¿Por qué tenemos terror de experimentar la muerte de un hijo?, ¿cuáles son las similitudes y diferencias de otras civilizaciones que entregaban a sus hijos a los dioses?, ¿pueden ser experiencias comparables? Para una respuesta comprensible sobre este difícil tema, es necesario adentrarse no solo en la religión como núcleo duro de la sociedad sino en el papel de la pureza como ordenador cósmico. Todo sacrificio alienta una expiación, un rito de expulsión de todo aquello considerado maligno, impuro, indigno o simplemente sucio. Al respecto, explica Taipe Campos que las prácticas de sacrificio ritual implican una sustitución simbólica. Muchas civilizaciones antiguas, incluidos los Cananeos, tenían la necesidad de sacrificar al hijo primigenio con el fin de calmar a las demandas de sus dioses o conferir estabilidad al sistema social. En ocasiones, la lógica subyacente en los sacrificios humanos parece orientarse a la alimentación o mantenimiento del orden social. La sangre como el corazón de un niño considerado puro sirve como alimento para los dioses. Estos actos, que fueron en principio demonizados por los conquistadores españoles, re-significaban la vida. El sacrificio de niños, a diferencia de aquellos llevados sobre prisioneros, guerreros o esclavos, se explica por medio de la tesis mausiana de don y contra-don (Taipe Campos, 2005). Dar a los dioses implica recibir su protección.

Por su parte, los arqueólogos Leonardo López Luján et al. (2010) describen detalles de los sacrificios sobre niños en el Templo Mayor de Tenochtitlán (en la cultura azteca). En este excelente trabajo, los autores sostienen que los ritos funerarios, la posición de las tumbas y la forma de recubrir a los cadáveres sugieren la idea de tres importantes puntos de investigación:

a) Las víctimas eran sacrificadas o entregadas a las divinidades vinculadas a la fertilidad o las condiciones de lluvia. 
b) Las víctimas eran hijos de personas que habían perdido su libertad, o sufrían alguna enfermedad incurable. El sacrificio involucraba una necesidad de restitución.

c) Algunas víctimas eran sacrificadas en ocasiones de guerra o antes de alguna batalla para que los dioses influyeran en el destino del grupo.

d) Existe entre la niñez y la guerra una correlación simbólica importante.

Los investigadores comentan que el "demonio Huitzipolochtli" exige el sacrificio de niños a los primeros moradores de Culhuacan. Esta ofrenda representa no solo la lealtad de la comunidad sino que sirve como mecanismo de verificación de esa devoción. El sacrificio no era vivido como un cierre abrupto, sino como la promesa de una vida eterna al lado de la deidad protectora, una vida sin ningún tipo de carencias, privaciones o frustraciones. Según los especialistas, la explicación para el sacrificio de niños se encuentra asociada a la migración forzosa, tema que si observamos con atención no parece ser ajeno a nuestros propios valores culturales arcaicos. Abraham (padre del judaísmo, cristianismo y del Islam) luego de su asentamiento definitivo, estuvo a punto de sacrificar a su hijo por pedido de Dios. Una razón convincente sugiere que ofrecemos a los dioses determinados sacrificios con el fin de obtener de ellos los recursos necesarios para la subsistencia, protección o determinado favor. La pureza por la corta edad de los niños sacrificados denota la pasividad de lo humano por sobre lo divino (misma pasividad que muestra el Rey Agamenón), una sumisión incondicional.

A diferencia de las comunidades antiguas, la modernidad ha rechazado lo divino anteponiendo la protección de los niños por sobre otros aspectos de la estabilidad social. En términos comparativos, si para los aztecas, cananeos o incas, sacrificar a sus primogénitos hubiese sido una medida efectiva de domesticar la naturaleza, para los modernos esa idea es inversamente proporcional al grado o umbral de control sobre el futuro, es decir, sobre la divinidad. Siendo la muerte el final de todo lo conocido, para el hombre contemporáneo el sacrificio humano queda completamente vedado. Su poder, por el contrario, radica en su distribución de la vida, la capacidad de predicción y la protección de sus generaciones más jóvenes. Al extender la vida, no es necesario negociar con el más allá o las figuras que moran fuera de los límites de la vida.

En el presente trabajo, intentaremos dilucidar cuál es el momento histórico del cambio de paradigma que lleva a crear sobre la figura de la mujer y del niño un objeto-tabú. Nuestra tesis apunta a que la organización moderna del trabajo relegó a los niños fuera del sistema productivo, dejando al hombre adulto por encima de otros grupos económicamente activos. Bajo el lema de dominación patriarcal que comienza con el industrialismo, y continúa en la modernidad, el niño se circunscribe a la esfera del hogar a fin de ser protegido de un mundo que se expresa hostil e inhóspito. 


\section{El miedo moderno}

¿Es cierto que tenemos más miedos que antes? Personas que dejan de enamorarse por miedo a sufrir o a tener hijos por miedo a que les sean arrebatados por el implacable destino. Nuestros miedos modernos parecen aflorar como nunca antes. En este sentido, Giddens (1991) argumenta convincentemente que el problema del riesgo es de percepción cuando el sujeto anticipa los peligros por medio de sus acciones. Este hecho marca la disociación entre tiempo y espacio, entre el selfy su madre. Si las expectativas de protección en la edad temprana están insatisfechas ellas se replicarán en la adultez generando un comportamiento patológico. Siguiendo el legado de la teoría del apego materno, Giddens afirma que los lazos de solidaridad fundan el sentido de vulnerabilidad y seguridad ontológica. Tanto la psicología como la psiquiatría han objetivado las relaciones de producción, incorporando teorías que apuntan a la protección de los niños y a la idea de trauma. El proceso de reflexibilidad ha creado una incesante cadena de cuestionamientos sobre el rol parental.

En The Transformation of Intimacy, Giddens (1992) traza un diagnóstico histórico respecto a la forma en que los sexos se han organizado. La organización del trabajo ha jugado un rol primordial en la configuración de la intimidad y de la identidad sexual. No hace mucho tiempo atrás, la cantidad de mujeres y niños fallecidos en partos o al momento de dar a luz era significativa. Los avances de la medicina puestos en la seguridad de la mujer generaron un doble impacto. Por un lado, una baja en las tasas de mortalidad infantil, y la creación de la "sexualidad plástica" cuyo único objetivo era la estimulación del placer. Tematizar sobre el sexo en términos científicos es una prueba de cómo actúa el proceso de reflexibilidad en la modernidad. Si para el hombre medieval, el sexo era una mera cuestión reproductiva, para el moderno es una forma de placer (no necesariamente asociada a la reproducción biológica). Giddens argumenta que esta sexualidad plástica puso a la mujer en un lugar excepcional incluso hasta el punto de amenazar el poder masculino. Ante esta tensión, la violencia del hombre para con la mujer intenta ser un mecanismo político disciplinario para un estado convulsionado donde las identidades sexuales están en constante negociación.

En la era del hedonismo, agrega C. Lasch, la protección de los hijos es terciarizada en instituciones especialmente adaptadas para tal fin, como los jardines maternales o las institutrices. A diferencia de Giddens, Lasch asume que el apego entre madre y niño se está quebrando, generando personalidades inseguras y narcisistas. Como efecto inmediato, los adultos que fueron socializados en atmósferas de inestabilidad constante sin soporte familiar se entregan al consumo desmedido, dejando el cuidado de sus hijos en terceras personas. Por dicho motivo, las sociedades modernas, además de negar la muerte, desarrollan un apego casi paranoico por la protección de los hijos 
(Lasch, 2000). De todos los temores circundantes en el imaginario colectivo de las sociedades occidentales, el temor a la muerte del hijo se encuentra entre los de mayor impacto psicológico (Korstanje, 2011).

El filósofo italiano Simone Regazzoni examina en profundidad el argumento de la serie televisiva Lost. De los muchos temas que aborda, hace énfasis en la ambigua relación entre la vida y la muerte. La muerte de Boone en la Isla se contrapone al nacimiento del hijo de Claire. A primera vista, el nacimiento de unos implica la muerte de otros pero hay más. Regazzoni sugiere que aquellos embarazos gestados dentro de la isla no solo no llegan a término, sino que culminan con la muerte de la madre. El hecho de vivir y llevar dentro del vientre la vida de otro, implica la propia muerte. La lógica del sacrificio, a grandes rasgos, exhibe la necesidad de dar para recibir. Los hombres dan a los dioses la vida, para evitar la muerte de la comunidad; uno salva a todos. Desde el mismo momento en que una persona nace, ya se encuentra muriendo.

En su libro Tótem y Tabú, Sigmund Freud argumenta convincentemente que etimológicamente la palabra tabú deriva de "un peligro sagrado" cuya raíz se remite a los primeros orígenes de las civilizaciones. Comprendido como un código no escrito, Freud sostiene que la función del tabú es aislar determinada persona u objeto del contacto diario. Evitar ese peligro antiguo se transforma en la base fundacional de toda sociedad (Freud, 1997; 1998). Douglas (2007) considera que los objetos tabú son importantes para las comunidades pues deben ser protegidos, preservados de tal forma que su aislamiento representa parte de su importancia. La idea misma de peligro permite al tabú mantenerse lejos de los hombres.

Tomando las contribuciones de Freud, Skoll \& Korstanje (2012) afirman que el riesgo abre una dicotomía -al igual que el tabú-. Confiere un velo de protección sobre el objeto tabú que reproduce la lógica económica. La sociedad funciona por medio de dos canales paralelos donde se distribuyen los bienes producidos. Los bienes que circulan en un sentido, no lo hacen en el otro y vice-versa. Un canal va a lo masivo, mientras el otro a lo particular. Los bienes que son de consumo generalizado, no son de las apetencias de las elites. El valor de los bienes masivos es notoriamente menor a los exclusivos. La relación entre bienes exclusivos y masivos es comúnmente re-significada por el riesgo. En tanto categoría discursiva, el riesgo confiere mayor poder a las elites pues permite mayor acumulación de bienes escasos a la vez que permite una mayor circulación de bienes masivos. Por ejemplo, pensar al terrorismo como un riesgo supone que el Estado se reserva para sí la producción de armas de destrucción masiva, interviniendo si se considera necesario terceros Estados, pero al mismo tiempo desregula la producción de armas domésticas dentro del mercado americano. De esta manera, la elite controla aquellos bienes estratégicos que de otra forma podrían hacer colapsar la sociedad. El tabú es una categoría subyacente de las sociedades primitivas, en tanto que su homólogo en las industriales es el riesgo. Ambos tabú-riesgo, confieren un valor incalculable al bien protegido. 
La protección del niño nos da un mensaje que amerita ser descifrado y que habla de nuestras inseguridades y desigualdades como sociedad.

\section{Los sacrificios y la teoría arqueológica}

Originalmente, pensaba la teoría antropológica que los sacrificios humanos se llevaban a cabo con el fin de alimentar una gran maquinaria que de otra manera se auto-destruiría. El derramamiento forzado o voluntario de sangre tenía como razón de existir, el rejuvenecimiento de los dioses y la no destrucción del mundo (Duverger, 1979). D. Carrasco (1999) explica que la violencia sacrificial es una relación dialéctica política entre el centro y su periferia. A la dimensión espacial que caracteriza estos rituales, se debe agregar la fundación de una primera ciudad cuya relación con las demás ciudades se basaba en la violencia física. Esta violencia como mecanismo de adoctrinamiento se sublima a través de los mitos cosmogónicos fundacionales.

Por su parte, Graulich (2005) sugiere que los sacrificios humanos llevados a cabo con niños durante el imperio Azteca, involucraban a padres que vendían a sus hijos o a esclavos cuyos hijos eran capturados luego de una batalla. El sacrificio de niños podía deberse a problemas específicos en los ciclos económicos y de fertilidad. Graulich admite que también se llevan a cabo sacrificios para que los dioses beneficien a la tribu en momentos de guerra o inestabilidad. Se sabe, admite el scholar, que la guerra puede ser comparable al niño no-nacido (unborn) porque se asuma que ésta es el motor del universo, al igual que la vida. Houston et al. (2003) recopilan evidencia arqueológica que explica que el rito sacrificial tiene relación con las grandes inauguraciones arquitectónicas. No obstante, a diferencia de Carrasco, afirman que los sacrificios pueden encontrarse tanto en las grandes ciudades como en las pequeñas. Olivier explica que la naturaleza de los ritos sacrifícales denota una idea previa de renovación donde los huesos de los sacrificados son asimilados como semillas. Para D. Dehouve, comprender los sacrificios no necesariamente implica estudiar los sacrificios humanos, sino también los animales. En perspectiva, la antropóloga sugiere que la investidura de un cargo denota cierto sacrificio inaugural. Las características del enemigo o el animal sacrificado pasan automáticamente al investido. Por ende, el sacrificio implica una forma nueva para ciertos grupos cazadores de ejercer poder.

Roman-Berelleza (1990), por último, afirma que la edad de la víctima es de capital importancia para la comprensión del fenómeno. Los niños, en casi todas las culturas, encarnan la pureza máxima de una sociedad. Su sacrificio les es entregado como un beneficio, un privilegio de entrar al mundo de los muertos protegidos por los dioses. Su muerte (sobre todo si estaba enfermo) ponía a los niños en ventaja respecto a aquellos que habían sido excluidos del sacrificio. Por el contrario, un estudio llevado a cabo por L. López Luján (2005; 2006), afirma que los sacrificios humanos se configuraban como ri- 
tuales luego de una migración forzosa donde se celebra la protección de los dioses. La escenificación de la juventud es un tema recurrente en los textos y estudios sobre comunidades que practican rituales humanos. Por ejemplo, los dioses mexicas toman formas de niños o aspectos juveniles (Durán, 1984).

Las cuestiones habituales respecto al sacrificio pueden enmarcarse en los siguientes tópicos:

a) relaciones de subordinación y miedo político,

b) ciclos reproductivos y de fertilidad,

c) problemas con la vitamina de ciertos alimentos y antropofagia,

d) migraciones forzadas y escasez de alimentos,

e) protección divina frente a desastres naturales o guerras, y

f) formas rituales tendientes a controlar el tiempo.

Los sacrificios de niños, como hemos discutido en la bibliografía especializada, tiene una función protectora que celebra toda una forma de vida y de ver el mundo. Toda migración forzosa y llegada a un nuevo ambiente representa un quiebre importante para la nueva comunidad. El sacrificio de un niño se lleva a cabo para lograr el beneplácito de los dioses que custodian el nuevo espacio a habitar (López-Luján y Olivier, 2010).

Tanto en Meso-América como en las sociedades incaicas, centradas en la dicotomía entre opulencia vs. carencia, se invocaba a los dioses por medio de un sacrificio. Ese ritual (llevado a cabo siempre en un centro ejemplar) entregaba a los dioses un niño, signo de pureza y vitalidad. Dicho ritual no se pensaba como un castigo, sino como un honor extraordinario. A cambio los dioses conferían a la comunidad un velo de protección. Por el contrario, en las sociedades modernas, la muerte de los niños adquiere un efecto totalmente inverso. Como veremos a continuación, la sociedad industrial introdujo modificaciones en sus códigos que generaron una doble dinámica. Por un lado, confirieron a la mujer y al niño una protección especial frente a un mundo complejo y hostil a la vez que puso al hombre al comando del orden económico. El niño que hasta ese momento participaba en las ganancias familiares como mano de obra, pasó a ser aislado al subterfugio del hogar por la legislación moderna. El terror a la muerte del hijo fagocita el propio orden patriarcal del hombre moderno y legitima su propia posición de privilegio frente a la mujer y a su progenie. Los derechos del niño son sancionados formalmente en Ginebra en el año 1924, ratificados luego de la gran guerra en 1948 con la "Declaración Universal de Derechos Humanos". El quiebre simbólico parece llevarnos a la forma en que las sociedades industriales han organizado su política económica interna. La creación y mantenimiento de los primeros sindicatos que legalizaron la huelga se asocia a la creación de una figura dominante de la masculinidad. En ese proceso, la mujer queda relegada al cuidado de los hijos en el hogar. 


\section{La sociedad del Sacrificio}

En su libro Una civilización incivilizada, Horst Kurnitzky (2005) desarrolla una hipótesis que permite una comprensión cabal del fenómeno económico global, sus consecuencias sobre la vida de las personas y la relación entre el sujeto y el poder público. Los hombres se diferencian de su medio ambiente por medio de signos. Partiendo de la base de que, como en la época moderna, sentimos terror y atracción por las grandes catástrofes, las comunidades pueden subsistir por medio del sacrificio. Sacrificar algo no solo exhibe la posibilidad de perderlo, sino de renuncia ante una posible pérdida. Anticiparse al desastre dando lo más preciado, abre un proceso de intercambio entre el mundo secular y el más allá.

En términos filosóficos, el sacrificio es (antes que nada) la base protectora de la civilización humana frente a la hostilidad del mundo. En busca de estabilidad las personas entregan sus bienes, cuerpos, o almas con el fin de obtener una ventaja respecto a otros grupos. Si bien denota la necesidad de cuidado, el sacrificio también engendra caos. La moneda como forma central de intercambio restringe el placer con el fin de evitar la pestilencia, la tragedia, el desastre. En un punto, el hombre se restringe de sus pasiones instintivas (civilización). No obstante no todo parece ser tan simple; la necesidad de intercambio deja abierta siempre una necesidad "no satisfecha", la cual lleva al sujeto "por el camino más corto" (incivilización). El engaño parece a grandes rasgos la piedra angular de la sociedad. Como éste se regula y se domestica, es el tema central de libro del profesor Kurnitzky. Desde su propia perspectiva, la política se ha economizado, optimizado a sus resultados y sólo es apelable según los efectos y no las causas de esos efectos. Donde antes interesaba el bien común, hoy subsiste la cultura de la imagen.

En situaciones indirectas, los políticos apelan a ciertas demandas con el fin de no perder su imagen positiva, pero son incapaces de movilizar los recursos necesarios para evitar las demandas. La psicología humana se debate sobre dos grandes tendencias, la satisfacción de los deseos y el apego a la ley. El primero libera los instintos en tal o cual dirección, mientras el segundo restringe la volición llevando al hombre a la sublimación transformadora. Ahora bien, las sociedades no se sustentan por el intercambio como han sugerido algunos padres de la antropología moderna, sino del culto al sacrificio. Todo sacrificio implica un balance entre deseo y represión para negociar un estado de estabilidad comunitaria. Todo grupo se mantiene unido gracias a que los deberes se distribuyen acordes a los derechos. En tanto "forma sustitutiva" el sacrificio exige un cuerpo (ofrenda) que es entregado a los dioses buscando un beneficio. La ofrenda es luego replicada con el fin de rememorar el intercambio (moneda).

Siguiendo este razonamiento, el intercambio, aspecto importante pero no necesario del sacrificio, contiene y resuelve la dicotomía entre restricción y placer. Por un lado el sacrificio bajo la forma del objeto-sacrificado mientras por el 
otro, del estímulo hedonista caracterizado por la ventaja. El manejo del dinero en el sistema capitalista apela al engaño para poder existir. La circulación de dinero evita que el sujeto tome lo que desea por decisión propia, resolviendo la necesidad de lidiar con otros quienes como él mismo desean los bienes ajenos. La circulación de moneda subvierte la relación entre las personas. A medida que mayores son las apetencias económicas, menores son las propensiones éticas de la persona para con otros. Las tendencias autodestructivas propias del egoísmo, deben ser disciplinadas por medio del temor y la esperanza. Los hombres y sus culturas recurren al sacrificio para evitar las calamidades pero también para nutrirse de la esperanza necesaria de que un tiempo mejor está por venir. El rito "sacrificial" abre la puerta del self con su futuro, es una forma de intentar domesticar lo que por naturaleza es incontrolable.

¿Cómo funciona la lógica del sacrificio en las sociedades modernas? Kurnitzky explica que el dinero ha reemplazado al sujeto-sacrificado. Cuando una persona entrega un bien a otra, el receptor debe contra-prestar una cuota de dinero (capital). En este acto ritual, ambas se restringen para sí mismas la gratificación de consumir lo que ceden. Pero la circulación de la masa monetaria encierra un riesgo. Históricamente, los imperios y los Estados subyacentes han promovido el ahorro en el ciudadano medio como una forma de vínculo ético a la vez que ellos mismos despilfarraron sus riquezas ya sea en actos de corrupción, construcciones megalómanas desmedidas, o expansiones territoriales. Los créditos financieros acompañan a las grandes campañas militares. En este sentido, la riqueza de cualquier nación dirime argumentos que llevan inevitablemente a restringir los recursos circulantes en el resto de la población. El ahorro se transforma en un discurso funcional a la expansión del Estado nacional. Sin embargo, la situación existente de pobreza general sólo es posible porque el capitalismo ha recurrido a un ahorro desmedido. La violencia es una reacción que intenta frenar el avance del ahorro, por tanto a mayor capacidad productiva y acumulativa de una sociedad mayores serán los umbrales de violencia permitida.

Pero ¿cuál es el límite exacto entre violencia y economía? Por medio de la violencia la contraposición de intereses -entre expoliación y preservaciónpermite a la sociedad poder funcionar. Cuando el sacrificio que es la base angular del intercambio se restringe a la acumulación compulsiva, los lazos sociales se debilitan. Sin la violencia que intenta componerlos a fronteras identitarias preestablecidas los grupos se dismembrarían. En palabras del autor:

"en la historia de la civilización, el dominio y el control de la violencia han sido elementos determinantes para la conformación de la sociedad, tanto de la violencia que surge del entorno como la que surge de la naturaleza humana. La domesticación de la violencia... fue la base para que los seres humanos se juntaran en sociedad, teniendo en las fiestas sacrificiales la expresión sensible de un sistema de obsequios y contra-obsequios: de economía. Transformados en actos de intercam- 
bio, los sacrificios constituyen la base de la reproducción social. Las relaciones entre los sexos, las relaciones al interior de las comunidades y entre las comunidades, la sociedad misma y sus relaciones con otras sociedades, todas están determinadas por su vínculo con la violencia. La limitación y el dominio de la violencia fue un estímulo esencial para el establecimiento de la sociedad, y la violencia surge de nuevo de la misma sociedad cuando ésta falla al mantener el equilibrio entre intereses contrapuestos" (Kurnitzky, 2005: 62).

En los procesos civilizatorios la violencia no desaparece, sino que persiste contenida, domesticada en diversos objetos. Los cultos antiguos autorizaban el sacrificio humano de mujeres hasta que progresivamente con la maduración económica, las personas fueron reemplazadas por animales. El proceso civilizatorio implica un control (pero no desaparición completa) de la violencia. En perspectiva, la violencia es un signo de la descomposición del lazo comunitario. Ante el miedo que resulta de la individuación, los nacionalismos y los grupos étnicos se transforman en techos protectores que evocan un mito primigenio, un primer discurso cuando los hombres vivían exentos de la corrupción. La paradoja, agrega Kurnitzky, es que los nacionalismos deben declarar la guerra para que sus valores sobrevivan, pero esa misma guerra contribuye al colapso de todo el sistema. Ante el descontento social, la identidad (idéntica) disuade a los rebeldes de tomar las armas. Los españoles (y otros grupos que actuaron como colonizadores) recurrieron a la identidad para desviar la discusión, haciendo similar aquello que por naturaleza no lo es, evitando en el "ethos" donde todos son iguales, la cooperación entre quienes se ven diferentes. La misma lógica puede aplicarse a los derechos universales o derechos humanos. ¿Son los derechos humanos aplicables a la protección de los más vulnerables?

Kurnitzky argumenta convincentemente que si bien por un lado los "derechos humanos" abogan por la libertad individual, cuando este derecho se hace colectivo a toda una nación, a toda una comunidad o grupo étnico, se lo anula. Si se acepta la autoridad del Estado, el ciudadano queda sujeto a la voluntad de su soberano. La comunidad nacional protege o explota a sus miembros acorde a sus intereses. Los derechos humanos adquieren estatus de universales y por ende son aplicables a todos los ciudadanos del planeta; empero, en el plano real, esta clase de derechos abstractos deben descansar sobre la doctrina de la soberanía nacional. En tanto discurso vació que alimenta los nacionalismos y sus efectos alienantes, los derechos humanos son construcciones sociales de escasa aplicación en la política. Si el miedo se fundamenta en la economía, ¿como explicamos nuestra tendencia a sobreproteger a nuestros hijos? Kurnitzky respondería que proteger al niño implica vedarlo como sujeto, no reconocerlo hasta el punto de alienarlo, despojarlo de todo su sentido de ser. En la próxima sección nos concentraremos en las raíces históricas de la tendencia a sobreproteger a los niños, la cual surge con la organización del trabajo. 


\section{La sociedad industrial}

Históricamente, los estudios sobre las relaciones laborales han enfatizado en la cuestión de clase dejando de lado la relación del género en la organización del trabajo. Para que las asimetrías ideológicas de género prosperen se tuvieron que dar dos cuestiones principales. Una posición pasiva de la mujer frente al varón dominante, y la reproducción de esas asimetrías en todas las instituciones de la sociedad industrial (Baron, 1991a). Por lo tanto, la hegemonía masculina sobre lo femenino tuvo éxito por consenso mutuo. El sindicato en tanto construcción social no solo ha sido creado por la lógica masculina de resistencia sino que además ha personificado un discurso de exclusividad y competencia donde la fuerza es el valor central.

Siguiendo este argumento, Baron sugiere que el concepto de la masculinidad ha sido históricamente empleado para definir una antigua tensión entre las grandes compañías y los sindicatos. Poniendo como ejemplo a la industria de los imprenteros, Baron admite que tanto el sindicato como las empresas pugnaron por definir los criterios de adscripción y capacitación para los futuros trabajadores. Los sindicatos no pudieron mantener en el tiempo sus cuadros de formación ya que no poseían el capital necesario para hacerlo. En su lugar adoptaron el criterio de masculinidad como forma divisoria entre el trabajador adulto y los niños o mujeres. Las teorías eugenésicas existentes coadyuvaron para resolver la tensión dándole al varón adulto anglosajón (WASP) una posición de privilegio frente a un "otro", el cual incluía varios colectivos como migrantes, mujeres y niños (Baron, 1991b). Los ideales de los sindicatos abrogaron por un sentido de lo que significa ser "un hombre", y ese sentido estaba construido sobre el pilar de la eficiencia. El varón no solo estaba destinado a trabajar por el bienestar colectivo de sus pares, es decir de su sindicato, sino también de su familia. El avance profesional individual y el bienestar de la familia fueron dos valores culturales en pugna en la cultura estadounidense (de Vault, 1991). Vemos que es precisamente que en esta época a la idea de sacrificio comienza a ser invertida para ser vinculada a una metáfora de superación o compromiso por el bienestar del grupo familiar. Es "el deber de" todo trabajador "sacrificarse" por la familia.

Sin embargo, la realidad racial y étnica de los Estados Unidos revela que existen grupos minoritarios que también entraban en escena. Dolores Janiewski (1991) reconoce que el racismo sureño es una fiel expresión de los miedos blancos a perder su control sobre la mujer, su progenie y la mano de obra esclava. La propia elite americana que amenazaba el orden feudal en el sur, resolvía la cuestión de los blancos pobres desempleados, pero al mismo tiempo generó un quiebre sustancial entre dos formas antagónicas de ver el mundo. El orden racial blanco del sur había sido construido sobre una supuesta superioridad del hombre blanco sobre otros subgrupos. Esta superioridad indicaba que el trabajo era un resultado del declive moral de aquellas especies, como la negra que se abrazaba a los vicios terrenales. 
Para una vida virtuosa, el discurso racista proponía un límite étnico que explicaba el orden preexistente. Claro que en dicha definición, el trabajador blanco pobre representaba una gran contradicción. Si a los negros se les había retirado la posibilidad de protesta, la pregunta del millón era: ¿cómo articular los derechos de aquellos blancos que no entraban en la elite sureña? La cuestión del honor fue crucial para resolver la dicotomía entre el blanco rico y el pobre excluyendo a los negros de la economía formal de los Estados Unidos. Si bien los blancos establecieron entre sí una solidaridad específica de raza (sobre la clase) donde (a diferencia de los negros), los trabajadores blancos gozaban de ciertos beneficios que debían retribuir con su lealtad, la realidad fue que el advenimiento de una fuerte crisis económica (ver pánico de 1873) generó una situación dual. Los blancos, asociados bajo el derecho sindical, compararon su situación con la esclavitud que sufrían los negros, y fue así que articularon un discurso de resistencia frente a la patronal. Esta resistencia encontró a una elite que recluyó más todavía la presencia negra en las fábricas, a la vez que ofrecía mayores regalos a una mayoría blanca descontenta por su precaria situación laboral. Pasarían algunas décadas, hasta los sesenta, para que los obreros negros entraran al mercado laboral en igualdad de condiciones a los blancos. Lo que resalta en forma elocuente el trabajo de Janiewski es que el sistema racista de los Estados Unidos abrió las puertas a su propia vulnerabilización.

La historia de los sindicatos revela que existen tres actores en pugna. El Estado, muchas veces pasivo frente a la lucha entre propietarios y trabajadores, los sindicatos que agrupan trabajadores especializados en una tarea específica, y los grupos empresariales. Cada táctica de mantenimiento del poder difiere acorde a cómo el sindicato se organiza. Esta idea es validada por el trabajo de M. Blewett (1991), quien afirma que algunos sindicatos han recurrido a la idea de masculinidad para mantener bajo control a otros grupos sociales como mujeres y niños. Estas medidas disciplinarias permitieron un mayor control en comportamientos y prácticas que eran difusas. Los grupos sindicales y sus líderes pactaron con sus respectivos empleadores cuotas reducidas de trabajadores jóvenes o niños, dándole al adulto mayor concentración de riqueza y fuerza. Como resultado, el sindicato no solo mantuvo la frontera entre los aptos y los ineptos para el trabajo, sino que también ha creado una forma de adoctrinamiento respecto a sus propios miembros. El trabajo organizado introdujo una nueva manera de pensar, un discurso donde ser trabajador implicaba masculinidad, habilidad y fortaleza. Por el contrario, otros sindicatos priorizaron el mejoramiento de sueldos frente a la patronal. Como esta táctica necesita de un gran número de brazos, sus políticas fueron incluir niños, mujeres y todo aquel que estuviese de acuerdo con los intereses del sindicato. La tesis de Blewett apunta a que cada grupo sindical ha manipulado el arquetipo de la masculinidad/feminidad acorde a sus intereses económico-políticos.

¿Puede ser la preocupación una forma sutil pero poderosa de dominación? E. Boris (1991) respondería, completamente. En la historia laboral de 
los Estados Unidos, los sindicatos alimentaron la idea de un trabajo sólo para los hombres que protegiera la vulnerabilidad de las mujeres y los niños. A la fallida acusación de que los niños eran mentalmente incapaces para el trabajo, se sucedió una batería de nuevas narrativas donde la victimización y la vulnerabilidad jugaron su carta más fuerte. Varios fabricantes de cigarrillos encontraron fuerte oposición de los sindicatos respecto a emplear mujeres y niños en el trabajo hogareño del armado de cigarrillos. En vistas de ello, la posición dominante del hombre sobre la cual basaba su poder el sindicato, enfatizaba en garantizar la seguridad del niño y su madre a vivir exclusivamente en la calidez del hogar. Como resultado, el hombre se posicionó por encima de ambos en la pirámide organizacional de la sociedad. El hombre fue el único conferido por el Estado con el derecho de negociar contrataciones y contratos, a la vez que la mujer fue, por ley, recluida al seno del hogar, generando una inquebrantable dependencia respecto al hombre. Este estudio nos recuerda cuán dominante y explotadora puede ser la idea de proteger a ciertos grupos a la vez que se los relega del sistema productivo.

Los sistemas financieros americanos no pudieron haber subsistido sino es por la acción de las compañías de seguro. En una sociedad capitalista, el riesgo es mitigado, aislado y procesado por el seguro. Una persona cuyas necesidades de protección no pueden ser satisfechas por los canales habituales, paga una cuota de capital a cambio de una protección simbólica. El seguro sólo tiene validez, obviamente, si el peligro no llega a concretarse. En este sentido, Kwollek-Folland (1991) recopila evidencia que prueba que desde sus inicios las compañías de seguros apelaron a una imagen arquetípica femenina y protectora, que emulara a la madre. El vínculo madre-hijo y todos los cuidados necesarios para el crecimiento del niño que se dan en el seno del hogar, fueron dos de los aspectos que promocionaron las compañías de seguro de vida. La figura de la madre hogareña fue construida corporativamente no solo aprovechando los valores culturales de la época con fines puramente comerciales, sino también para reforzar un arquetipo ideológico con un mensaje específico para toda la sociedad. La protección, la niñez y la mujer se encuentran inextricablemente ligadas. Estas mismas observaciones fueron plasmadas en la decoración interna y la arquitectura de las oficinas que ofrecían productos vinculados a los seguros de vida. La idea, a grandes rasgos, era recrear la calidez del clima hogareño y la protección de la madre. Kwollek-Folland afirma que si bien la figura de una madre protectora fue funcional a los intereses de algunas compañías de servicios, en el fondo la lógica paternalista de sumisión quedaba solapada; ello no significa que no existiera. El comando de este tipo de corporaciones estaba manejado por hombres. La creencia mitológica de una corporación hogareña (una gran familia) parecía no coincidir con la real subordinación que las mujeres, la mayoría de ellas secretarias, tenían respecto a sus empleadores hombres. Incorporando un sentido feminizado del mundo, el hombre anula el sentido de la muerte demostrando que la misma puede ser racionalizada, medida 
y hasta incluso controlada por la acción del hombre. La predicción junto al manejo estadístico de probabilidad se transforman en dos valores esenciales de la sociedad capitalista moderna.

De diversas maneras, la mujer comenzó a ser controlada de forma tal que no pudiera acceder a trabajos clave de la economía. Incluso en la restauración y la hotelería, industria manejada primariamente por mujeres ya que éstas emulaban el arquetipo femenino de protección, los sindicatos ejercieron una gran presión sobre las camareras, primero prohibiéndoles que expendan alcohol a sus clientes (lo cual afectaba seriamente sus propinas) y luego legislando una serie de leyes que prohibían el trabajo nocturno. La excusa era simple a grandes rasgos, garantizar la integridad de la mujer, que en el mejor de los casos es proteger la integridad de la familia. Cada grupo peleaba por lo que consideraba eran sus intereses en juego, las mujeres denunciaban la dominación masculina, acusación que era contrarrestada por parte de los hombres argumentando que las mujeres eran el sostén del hogar. Limitar el trabajo femenino era para los sindicatos algo más que una táctica política, representaba una máxima ético-moral (Cobble, 1991).

La organización del trabajo industrial sentó no solo las bases para la creación del capitalismo moderno, sino que creó dos movimientos paralelos, uno centrífugo (de expulsión hacia fuera) y otro centrípeto (de inclusión hacia dentro). En su trabajo sobre los primeros anarquistas, J. Joll (1979) explica que la organización del trabajo en los Estados Unidos y Europa estuvo plagada de tensiones políticas entre la masa de obreros y sus empleadores. Los grupos anarquistas y socialistas, favorecidos por la abierta migración de la década de los 80 a América, modificaron la forma de re-pensar la lógica productiva. El aumento de la expansión productiva necesitaba de más brazos pero más injustas se tornaban las relaciones de explotación. El crecimiento de los Estados nacionales, a costa de una gran masa de trabajadores, generó un punto de tensión con la lucha sindical. Muchos anarquistas dejaron su lucha armada (terrorismo) y volcaron sus energías a educar a los trabajadores en obtener una fuerte conciencia de clase. En forma interna, el terrorismo no solo fue disciplinado por medio de la regalía financiera (sueldo) sino que además cerró las fronteras a ciertos elementos indeseables (Skoll \& Korstanje, 2013). Esta dinámica centrífuga otorgó a los trabajadores de todas las reglamentaciones y disposiciones legales vigentes con el fin de reglamentar la lucha por el capital a través de la huelga. De la misma manera, expulsó hacia fuera de las fronteras todo tipo de lucha violenta a la cual denominó "terrorismo". En forma centrípeta, es decir hacia el centro, Estados Unidos vulnerabilizó a la mujer y a los niños con el fin de darle mayor autonomía y poder a sus sindicatos. Como ya hemos visto, la reglamentación laboral sobre la cual los sindicatos ejercían su control, daba a la figura paterna la dimensión necesaria para construir una pirámide productiva jerárquica donde el hombre anglosajón estuviera por encima de otros grupos. Tanto la posición de los niños y las mujeres que ocupaban un rol activo en el mercado laboral de muchas industrias (debido 
a la pauperización del trabajo y a los bajos salarios) como la necesidad de un mejoramiento en los sueldos de los obreros hombres, fueron variables importantes que explican un quiebre epistemológico importante en la forma en que se concibe la figura del hogar. Protegidos pero relegados del sistema productivo, se introduce el arquetipo del hombre como único protector (coactivo) del hogar y de la patria. Desde entonces, se ha impuesto un doble discurso que combina protección con sumisión. El terror por la muerte de los hijos representa un discurso por medio del cual el régimen patriarcal puede perpetuarse (incluso en la modernidad tardía).

\section{Conclusión}

Tanto para las culturas antiguas como para las modernas, los niños representan lo más valorado y preciado. Sus diferencias culturales, resultantes de sus capacidades de adaptación, no obstante, dan diversos tratamientos al tema del sacrificio de los niños. Lo que subyace en el fondo de esta cuestión, es la relación de la comunidad con su ambiente. Comunidades en ambientes hostiles recurren a ritos expiatorios de sacrificios con el fin de logar la protección de sus dioses. El objetivo último de todo rito sacrificial es controlar la incertidumbre. Como hemos demostrado en este trabajo, la sociedad industrial ha sido un punto de quiebre respecto a la protección sobre los niños. Con el derecho reglamentado para el cuidado de los menores, el hombre tomó posesión real de los medios de producción con el fin de lograr un control hegemónico sobre otros subgrupos, no solo disciplinando a la mujer sino circunscribiéndola a límites establecidos, como el hogar o ciertos trabajos mal pagos.

En el Cuadro 1 enumeraremos las características principales de las sociedades antiguas y modernas, diferencias que explican por qué mientras las primeras recurren al sacrificio humano, las segundas lo prohíben.

Cuadro 1. Características comparativas sociedades industriales y pre-industriales

\begin{tabular}{|l|l|l|}
\hline Comportamiento & Sociedad Preindustrial & Industrial Moderna \\
\hline Sacrificio de niños & Selectivo a grupos & Prohibido \\
\hline Religión & Apego a la trascendencia & Mundo Secular \\
\hline Mortalidad & Alta & Baja \\
\hline Posición frente a la muerte & Aceptación & Negación \\
\hline Sistema productivo & Agrícola-tradicional & Capitalista-instrumental \\
\hline Trabajo & Todos los integrantes & Restringido al hombre \\
\hline
\end{tabular}

Fuente: Elaboración propia.

Una explicación profunda de las diferencias enumeradas sugiere que la sociedad industrial ha creado un cambio sustancial en la forma de ver el mundo, respecto a las primitivas. Ese cambio se orienta a una fase donde la muerte ha sido completamente negada. Las tecnologías existentes del mundo 
moderno han logrado con éxito expandir la expectativa de vida hasta límites impensados. No obstante, como sugiere Phillipe Aries (2011), esa posibilidad ha hecho de la muerte un tema difícil de digerir. La falta de familiaridad del hombre moderno respecto a la posibilidad de morir, hace del mundo secular un espacio que debe ser controlado bajo la lógica de expropiación instrumental. El shock psicológico que genera la muerte en este tipo de sociedades es mayor en comparación a las pre-industriales. El mundo capitalista no solo prohibió los sacrificios humanos haciendo de la mujer y los niños su principal preocupación, sino que puso al hombre mismo en el control total del sistema productivo biológico y económico. En el momento en el cual el trabajo en fábricas y oficinas comienza a ser restringido a las mujeres y niños, amparado en la protección de ambos, surge el temor como forma de preservar el estatus masculino. Las desigualdades de la sociedad industrial se anclan y se reproducen gracias al falso paternalismo del hombre hacia su familia. El trabajo y el dinero asociados estrictamente al mundo de los hombres, en un espacio siempre hostil implica relegar a los niños al cuidado de su madre. Cualquier aspecto que pueda atentar contra la seguridad ontológica del niño-sagrado es un ataque al orden económico masculino-patriarcal. En este sentido, cabe preguntarse cuáles serán los efectos mediatos de la emancipación de la mujer en el mundo del trabajo. Por lo pronto, la subordinación de la mujer respecto al hombre pareciese verse inalterada por la desigualdad de género.

\section{Referencias bibliográficas}

\section{Fuentes secundarias}

ARIES, P. (2011). El Hombre ante la muerte. Buenos Aires: Taurus.

BARON, A. (1991a). Gender and labor history, learning from past looking to the future. Work Engendered. Toward a new history of American Labor. Ithaca: Cornell University Press, pp. 1-46.

BARON, A. (1991b). An other side of gender antagonism at work: Men, boys and the remasculinization of printers work, 1830-1920. In: BARON, A. (editor). Work Engendered. Toward a new history of American Labor. Ithaca: Cornell University Press, pp. 47-69.

BORIS, E. (1991). A Man's Dwellling House is his castle? Tenement House Cigarmaking the Judicial Imperative. In: BARON, A. (editor). Work Engendered. Toward a new history of American Labor. Ithaca: Cornell University Press, pp. 93-113.

BLEWETT, M. (1991). Manhood and the Market: the politics of gender and class among the textile workers of Fall River Massachusetts, 1870-1880. In: BARON, A. (editor). Work Engendered. Toward a new history of American Labor. Ithaca: Cornell University Press, pp. 70-91. 
CARRASCO, D. (1999). City of Sacrifice. The Aztec Empire and the Role of Violence in Civilization. Boston: Beacon Press.

COBBLE, S.D. (1991). Drawing the Line: the construction of gendered work force in Food Service Industry". In: BARON, A. (editor). Work Engendered. Toward a new history of American Labor. Ithaca: Cornell University Press, pp. 216-242.

DE VAULT, I. (1991). Give the boys a trade. In: BARON, A. (editor). Work Engendered. Toward a new history of American Labor. Ithaca: Cornell University Press, pp. 191-215.

DEHOUVE, D. (2008). El venado, el maíz y el sacrificado. Diario de Campo. Cuadernos de etnología, № 4, pp. 1-39.

DOUGLAS, M. (2007). Pureza y Peligro: un análisis de los conceptos de contaminación y tabú. Buenos Aires: Nueva Visión.

DURÁN, FRAY D. (1984). Historia de la Indias de Nueva España e Islas de la Tierra Firme, 2 vols. México: editado por Ángel Ma. Garibay K.

DUVERGER, C. (1979). La fleur létale. Économie du sacrifice aztèque. París: Seuil. GRAULICH, M. (2005). Le sacrifice humain chez les Aztèques. París: Fayard.

FREUD, S. (1997). Tótem y Tabú: Algunas Concordancias en la vida anímica de los salvajes y de los neuróticos. En: Obras Completas. Buenos Aires: Amorrortu Editores, vol. 13.

FREUD, S. (1998). Análisis de la Fobia en un niño de cinco años. En: Obras Completas. Buenos Aires: Amorrortu Editores, Volumen 10.

FOUCAULT, M. (2006). Seguridad, Territorio, Población: curso en el Collage de France (1977-1978). Buenos Aires: Fondo de Cultura Económica.

GIDDENS, A. (1991). Modernity and Self-Identity. Self and society in The late modern age. Stanford: Stanford University Press.

GIDDENS, A. (1992). The Transformation of Intimacy. Sexuality, Love, and Eroticism in modern societies. Oxford: Polity Press.

HOUSTON, S.D.; ESCOBEDO, H.; SCHERER, A.K.; FITZSIMMONS, J.L. \& CHILD, M. (2003). Maya Death at Piedras negras Guatemala. En: Antropología de la Eternidad. La muerte en la cultura Maya. CIUDAD RUIZ, A.; RUZ SOSA, M.H. \& Iglesias, J. (editores). Madrid: Sociedad Española de Estudios Mayas y Centro de Estudios Mayas, pp. 113-143.

JANIEWSKI, D. (1991). Southern honor, Southern deshonor: managerial ideology and the construction of gender, race and class relations in souther industry. In: BARON, A. (editor). Work Engendered. Toward a new history of American Labor. Ithaca: Cornell University Press, pp. 47-69. 
JOLL, J. (1979). The Anarchists. Cambridge: Methuen.

KORSTANJE, M. (2011). Decodificando la Esencia del Mal, o del terror a la muerte del hijo. Revista Mad, Vol. 24, pp. 76-92.

KURNITZKY, H. (2005). Una civilización incivilizada. México: Océano.

KWOLEK-FOLLAND, A. (1991). Gender, Self and work in the life insurance industry, 1880-1930". In: BARON, A. (editor). Work Engendered. Toward a new history of American Labor. Ithaca: Cornell University Press, pp. 168-190.

LASCH, C. (2000). La Cultura del Narcisismo. Barcelona: Andrés Bello.

LÓPEZ-LUJÁN, L. (2005). The Offerings of the Templo Mayor of Tenochtitlan. Albuquerque: University of New Mexico Press.

LÓPEZ-LUJÁN, L. (2006). La Casa de las Águilas, 2 vols. México: FCE/NAH/Harvard University.

LÓPEZ-LUJÁN, L. y OLIVIER, G. (2010). Nuevas perspectivas sobre el sacrificio humano entre los mexicas. México: Instituto Nacional de Antropología e Historia. Disponible en Internet: http://www.mesoweb.com/about/articles/Huitzilopochtli. pdf

LÓPEZ LUJÁN, L.; CHÁVEZ BALDERAS, X.; VALENTín, N. y MONTÚFAR, A. (2010). Huitzilopochtli y el Sacrificio de niños en el Templo Mayor de Technotitlán. En LÓPEZ LUJÁN, L. y GUILHEM, O. (editores). El Sacrificio Humano, en la tradición religiosa mesoamericana. México: Universidad Nacional Autónoma de México, pp 367-394.

OLIVIER, G. (2006). Crítica de libros: sobre Michel Graulich, Le sacrifice humain chez les Aztèques, París, Fayard, 2005. Historia Mexicana, vol. 221, pp. 287-301.

REGAZZONI, S. (2010). Lost, la filosofía. México: Editorial Grijalbo.

ROMÁN-BERRELLEZA, J. (1990). El sacrificio de niños en el Templo Mayor. México: INAH/GV Editores.

SKOLL, G. \& KORSTANJE, M. (2012). Risks, Totems, and Fetishes in Marx and Freud. Sincronía: a Journal for the Humanities and Social Sciences, Año XVII, № 61 , pp. $1-27$

SKOLL, G. \& KORSTANJE, M. (2013). Constructing an American fear Culture from red scares to terrorism. International Journal for Human Rights and Constitutional Studies, Vol. 1, № 1, pp. 1-34.

TAIPE CAMPOS, N. (2005). La Sustitución como forma de Sacrificio. Gazeta de Antropología, Texto 21. Disponible en Internet: http://www.ugr.es/ pwlac/ G21_06NestorGodofredo_Taipe_Campos.html . Extraído 01-10-2012. 